\title{
IMMOBILISATION OF METALS IN THE ADSORPTION PROCESS
}

\author{
Małgorzata Wojtkowska
}

The Faculty of Building Services, Hydro and Environmental Engineering, the Warsaw University of Technology,

00-653 Warsaw, Poland

malgorzata.wojtkowska@pw.edu.pl

\begin{abstract}
An important indicator of pollution is the bottom sediments of reservoirs and watercourses, where metals are strongly bound. Depending on the factors at the bottom of the reservoir, metals can be a secondary source of pollution of the water body. Therefore, developing methods to immobilise metals in bottom sediments is one of the priorities for caring for surface water quality.
\end{abstract}

Key words: heavy metals, bottom sediments, bentonite, adsorption

\section{Introduction}

Today's technological development is having a major impact on the natural and human environment. This development is coupled with the pollution that enters the environment and increases in direct proportion to the demands of society. Environmental pollution results mainly from the economic activities of the energy sectors and heavy industry. An important source is agricultural areas, where pollution from mineral and organic fertilisers predominates, contributing to the pollution of soil and water in reservoirs and watercourses. An increase in the concentration of micropollutants, especially heavy metals, is currently observed in the environment. The sources of heavy metals are wastewater discharged from cities, mines and industrial plants, but also infiltration from landfills, run-off from agricultural areas and areas associated with dust emissions from power plants and steelworks [2].

Due to anthropogenic factors, elevated heavy metal content enters water bodies. In the natural environment metals occur in trace amounts not exceeding $1 \%$ of the total concentration [1]. As a result of binding with solid particles and sedimentation process, chemical compounds of these elements are accumulated in bottom sediments. The form in which metals occur in sediments indicates their different mobility [3].

Increased elemental content in sediments leads to a decrease in surface water quality and can lead to poisoning or contamination of organisms living in ecosystems [4].

Since metals entering the aquatic environment are bound in the solid phase, one way to remove or neutralise harmful elements is to use an adsorption process. The best way to immobilise heavy metals is to use a sorbent with the least negative impact on the biochemical state of the reservoir. One of the most commonly used heavy metal sorbents is bentonite.

The study was undertaken to check the sorption efficiency of the bentonite compound and to determine its effectiveness for selected elements $(\mathrm{Cu}, \mathrm{Ni}, \mathrm{Cd}, \mathrm{Zn}$ and $\mathrm{Pb})$. In our study, adsorption was carried out in a "solid-liquid (solution)" system. As a result of the deposition of atoms, particles, ions on the adsorbent surface, a layer tightly covering the adsorbent medium is formed. This leads to a state in which, when the concentration of the solution is changed, its particles move together on the surface of the adsorbent.

\section{Methods and Results}

Samples of bottom sediments were collected from a lake located in the Warsaw agglomeration, on the area belonging to the Natura 2000. Bentonite was used as an adsorbent. The main aim of the study 
was to check the effectiveness of heavy metals immobilisation in bottom sediments. The total content of metals in bottom sediment without and with the addition of bentonite was determined in the study. The most mobile ion-exchange fraction of metals was also determined.

The obtained results clearly indicate the effectiveness and efficiency of element sorption on bentonite. The studies showed that the metals studied $(\mathrm{Cu}, \mathrm{Cd}, \mathrm{Zn}, \mathrm{Ni}$ and $\mathrm{Pb})$ were characterised by selective reaction with bentonite. The best stabilisation was found for lead and zinc. Copper and cadmium were absorbed to a lesser extent, which made it necessary to apply a higher dose of the sorbent or use a mixture allowing to stabilise the studied trace elements more effectively. Nickel was characterised by the lowest degree of adsorption by bentonite, which in the process of water reservoir stabilisation imposes the necessity to use other sorbents with higher nickel binding degree.

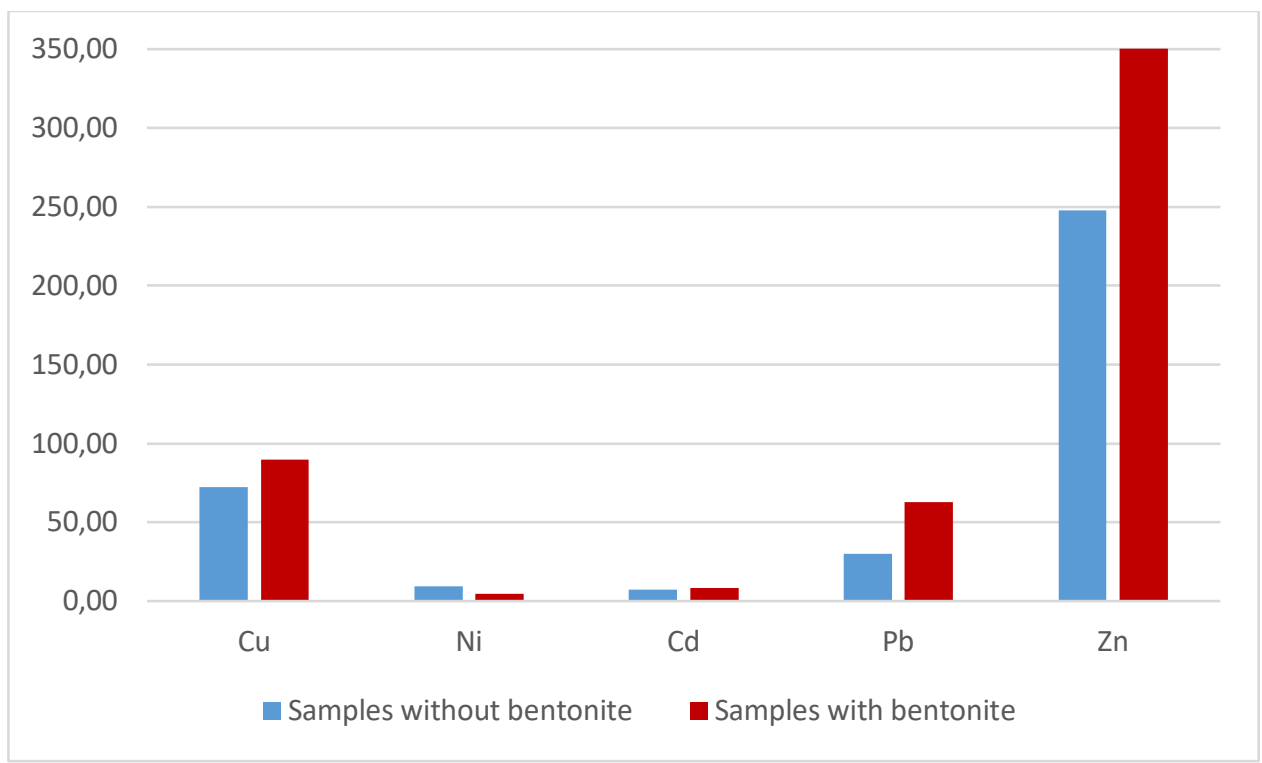

Fig. 1. Average content of heavy metals in the sediment [mg/kg s.m.]

On the basis of the study of the total metal content and the mobile fraction it was found that the ion-exchange fraction, representing a very small percentage of the total metal content, had a similar proportion in all sediment samples for individual metals. The average content of the ion exchange fraction in comparison to the total content of copper and zinc is $0.22 \%$, nickel and lead $25 \%$, cadmium $8.5 \%$.

The lower values of heavy metals in the ion-exchange fraction determined in the sediment with the addition of bentonite indicate that bentonite bound the mobile forms of metals. This testifies to the effectiveness.

Based on the results obtained, it was found that bentonite has sorption capacity for heavy metal ions present in solutions. At the same time, a selective sorption capacity for individual heavy metals is observed, which is due to ion competition. In terms of the level of adsorption, the heavy metals studied can be ranked as follows:

$$
\mathrm{Pb}>\mathrm{Zn}>\mathrm{Cu}=\mathrm{Cd}>\mathrm{Ni}
$$

The results of other researchers [1] who evaluated adsorption on bentonite indicate a different order of the metal sorption series with respect to selectivity:

$$
\mathrm{Pb}>\mathrm{Cu}>\mathrm{Zn}>\mathrm{Ni}>\mathrm{Cd}
$$


Similarities can be observed for the element with the highest adsorption capacity $(\mathrm{Pb})$ and the elements with the lowest absorption capacity ( $\mathrm{Ni}$ and $\mathrm{Cd}$ )

The use of bentonite significantly binds and immobilises metals in the solid phase. Due to changes in chemical parameters resulting from inactivation of positive heavy metal ions, it will be necessary to monitor and adjust the $\mathrm{pH}$ of water and bottom sediments in the reservoir. In the case of improperly calculated adsorbent dose depletion of the sediment layer may occur, not only in heavy metals, but also in $\mathrm{H}+$ ions, which will cause acidification of the sediment environment and the overlying water.

\section{Conclusions}

The use of bentonite as a sorbent is a highly effective way to improve the quality of bottom sediments contaminated with trace elements. The sorption time of metals on bentonite is short. Studies indicate that bentonite is selective in the sorption process for individual elements. This method does not imply any serious changes in the sediment chemistry and does not adversely affect its biochemical values. The use of this natural sorbent positively influences the character of sediments and leads to stabilisation and immobilisation of metals contained in them. The only necessity is to constantly monitor the $\mathrm{pH}$ of the sediment and a possible correction by liming the tank.

\section{References}

[1] Alloway B.J. \& Ayres D.C., Chemiczne podstawy zanieczyszczenia środowiska, , Warszawa 1999

[2] Bojakowska I., 1995. Wpływ odprowadzania ścieków na akumulację metali ciężkich w osadach wybranych rzek Polski, Państwowy Instytut Geologiczny, 55

[3] Wojtkowska M., Bogacki J., Witeska A., 2016. Assessment of the hazard posed by metal forms in water and sediments, Science of the Total Environment, 551-552, 387-392, https://DOI:10.1016/j.scitotenv.2016.01.073

[4] Wojtkowska M., 2020. Heavy metal pollution of water and bottom sediments of the Wilanowskie Lake, w: Desalination and Water Treatment, 191, 110-117, DOI:10.5004/dwt.2020.25178 